\title{
A EDUCAÇÃo INFANTIL E AS PRÁTICAS PEDAGÓGICAS DESCOLONIZADORAS: POSSIBILIDADES INTERCULTURAIS
}

\author{
Child education ANd DeCOlonizing PEDAGogical \\ PRACTICES: INTERCULTURAL POSSIBILITIES
}

\begin{abstract}
Tarcia Regina da Silva Doutora em Educação pela Universidade Federal da Paraíba. Professora adjunta da Universidade de Pernambuco. PE. Brasil tarcia.silva@upe.br

Adelaide Alves Dias Doutora em Educação pela Universidade Federal Fluminense. Professora titular da Universidade federal da Paraíba. PB. Brasil. adelaide.ufpb@gmail.com
\end{abstract}

\begin{abstract}
Resumo: Esta pesquisa baseia-se no pressuposto de que uma Educaçáo pautada em/para os Direitos Humanos, que incorpora desde a Educação Infantil, o direito à diferença na perspectiva intercultural tem contribuído para que as crianças e negras construam positivamente sua identidade. $\mathrm{O}$ objetivo principal desta pesquisa foi analisar as práticas pedagógicas das professoras da Educação Infantil de um Centro Municipal de Educação Infantil (CMEI) no Recife que estão comprometidas com a valorização da diversidade étnico-racial. Nesse contexto, buscamos responder: quais práticas educativas estão sendo desenvolvidas por essa equipe que são comprometidas com uma educação antirracista? Para tal, recorremos aos pressupostos da pesquisa qualitativa e ao estudo de caso. Os sujeitos da pesquisa foram: a gestora, a coordenadora, uma professora e duas auxiliares de desenvolvimento infantil. Utilizamos a entrevista semiestruturada como instrumento de coleta de dados. As análises evidenciaram que as práticas desenvolvidas no CMEI partem do princípio da incorporação do outro como verdadeiramente outro.
\end{abstract}

Palavras-chave: Educação em/para Direitos Humanos. Educação Infantil. Interculturalidade. Práticas Pedagógicas. Relações Étnico-Raciais.

Aвstract: This research is based on the assumption that an Education based on / for Human Rights, which incorporates since Early Childhood Education, the right to difference in the intercultural perspective has contributed to children and blacks to positively build their identity. The main objective of this research was to analyze the pedagogical practices of the teachers of Early Childhood Education of a Municipal Education Center (CMEI) in Recife that are committed to the valorization of ethnic- 
racial diversity. In this context, we seek to answer: what educational practices are being developed by these teams that are committed to an antiracist education? For this, we used the assumptions of qualitative research and case study. The research subjects were: the manager, the coordinator, a teacher and two child development assistants. We used the semi-structured interview as an instrument of data collection. The analyzes showed that the practices developed in the CMEI start from the principle of incorporating the other as truly another.

Keywords: Education in/for Human Rights. Early Childhood Education. Interculturality. Pedagogical Practices. Ethnic-Racial Relations.

\section{Introdução}

De acordo com Abramowicz (20II), vivemos uma mesmice na vida acadêmica, que nos leva à condenação. Logo, precisamos sair desse ponto de estagnação e de denúncia do racismo na escola, reconhecendo e visibilizando que muitos educadores estão comprometidos com a promoção de açóes que têm contribuído fortemente para que a população negra possa recriar suas histórias, ampliando as possibilidades de reinvenção e resistência. Nesse contexto, reconhecemos que "precisamos investigar onde aparece um novo mundo de existência comunitário ou individual, onde estão esses germes? Necessitamos reinventar a vida, ou seja, preci20II, p. 36) A partir dessa assertiva, afirmamos como Petronilha Silva (20IO) que muitos educadores estão comprometidos com o "enegrecimento" da educação.

No processo de enegrecer, educam-se, superando a arrogância dos que se têm como superiores e o retraimento dos que são levados a se sentir inferiorizados. [...] É importante salientar que o enegrecer da educação para os negros significa sentirem-se apoiados, com o reconhecimento, pela sociedade, da história e cultura dos africanos e seus descendentes, a construir livremente seu pertencimento étnico-racial, a exercer com dignidade sua cidadania. Para os não negros significa se tornarem capazes de deslocar o olhar de seu próprio mundo e, dessa forma, conseguir compreender distintos modos de pensar, de ser, de viver. (SILVA, 20Io, p. 4I-42) 
Nesta pesquisa, move-nos o desejo de evidenciar as práticas que estão enfrentando o desafio que a descolonização nos propóe, reconhecendo que os currículos não são naturais, mas construções históricas de sujeitos. Logo, podem ser reinventadas criando novas situaçóes pedagógicas e novas relaçóes sociais. Assim, o objetivo principal da pesquisa que origina este artigo é analisar as práticas pedagógicas das professoras de um Centro Municipal de Educação Infantil (CMEI) da cidade de Recife, Pernambuco, que estão comprometidas com a valorização da diversidade étnico-racial das nossas crianças, com a descolonização do saber, buscando responder às seguintes indagaçôes: Quais práticas educativas estão sendo desenvolvidas pela equipe do CMEI que são comprometidas com uma educação antirracista? Quais os fundamentos teóricos estão subjacentes a essas práticas? Para tal, recorremos aos pressupostos da pesquisa qualitativa e ao estudo de caso, tendo como sujeitos: a gestora, a coordenadora, uma professora e duas auxiliares de desenvolvimento infantil do CMEI investigado, tendo como recurso de coleta de dados a entrevista semiestruturada.

Nosso posicionamento parte do multiculturalismo crítico proposto por MClaren (1997), que coaduna com as propostas de interculturalidade defendidas por Vera Maria Ferrão Candau (2005; 20I I; 20I2) e Catherine Walsh (2009a). Esse estudioso e essas estudiosas propóem uma educação a ser construída baseada no desvelamento das formas de colonialidade, associando-se ao combate a todas as formas de exclusão, negação e subalternização de que os grupos racializados são vítimas no/e através do currículo; opondo-se às práticas pedagógicas que privilegiam uns grupos em detrimento de outros, naturalizando a diferença e ocultando as desigualdades que as configuram; apoiando, valorizando e conhecendo a organizaçáo e atuação dos educadores que lutam e se opóem ao processo de desumanização e subordinação da humanidade.

A interculturalidade crítica (WALSH, 2009a) tem como motes centrais as relaçóes de poder, o padrão de racialização vigente e o como a diferença tem sido construída em função desses contextos. É também nessa perspectiva que esta pesquisa se organiza, reconhecendo "o problema estrutural colonial racial e sua ligação ao capitalismo de mercado." (WALSH, 2009b, p. 6-7) Mas essa não é uma perspectiva que se limita 
apenas ao campo político. Ela também se solidariza com todas as formas de exclusão, negação e subalternização às quais os grupos racializados estão expostos, naturalizando a diferença e ocultando as desigualdades que as configuram, bem como "os seres de resistência, insurgência e oposição, os que persistem, apesar da desumanização e subordinação.” (WALSH, 2009a, p. 23)

Para essa autora, a interculturalidade crítica no campo educativo ultrapassa a discussão da diversidade étnico-cultural e se insere numa questão mais ampla que é o problema da ciência em sua essência, ou seja, a forma como a ciência, elemento estruturante da modernidade/ colonialidade, fortaleceu a conservação de uma hierarquia racial na qual o modelo de homem branco, principalmente europeu, é tido como referência. Possibilita ainda a elaboração de novas perspectivas epistemológicas que pluralizam esse conhecimento tido como universal, a partir do questionamento das relaçóes de poder a que esses conhecimentos foram submetidos. Para Candau (20I2), a interculturalidade é uma perspectiva que se ajusta à construção de sociedades democráticas e inclusivas, nas quais se busca encadear políticas de igualdade a políticas de identidade. A interculturalidade afeta as várias dimensóes da educação, possibilitando um movimento de crítica e autocrítica que incrementa a interação e a comunicação recíproca entre diferentes sujeitos e grupos sociais.

Diante dessas consideraçóes, a interculturalidade nos convida a reinventar a escola (CANDAU, 20I2) a partir de novos olhares, práticas pedagógicas, estratégias de vivências que podem considerar os saberes ancestrais [...] "como conhecimentos que têm contemporaneidade para criticamente ler o mundo, e para compreender, (re)aprender e atuar no presente." (WALSH, 2009a, p. 25) A interculturalidade nos convida a um projeto decolonial (WALSH, 2009a), ou melhor, a um projeto que questiona e busca o enfrentamento da matriz colonial do poder em todas as suas formas: colonialidade do poder (QUIJANO, 2005), do saber, do ser e da cosmogônica da mãe natureza e da vida humana. Nessa perspectiva é que este artigo se organiza. 


\section{Educação em/para os direitos humanos: uma alternativa para visibilizar as diferenças desde a educação infantil}

De acordo com Piovesan (2006), se a primeira fase dos Direitos Humanos tinha como principal marca a proteção geral que evidenciava o temor da diferença baseada na igualdade formal, o que levou ao extermínio dos diferentes no contexto do nazismo, na atualidade admite-se que não se podem tratar os sujeitos de maneira genérica, geral e abstrata. Nesse quadro, cabe olhar para os indivíduos nas suas peculiaridades e particularidades, pois é em razão de suas especificidades que eles tensionam por resoluçóes específicas, peculiares e exclusivas. Tal contexto favorece a promoção de direitos e não a sua aniquilação, possibilitando que grupos até entâo invisibilizados sejam reconhecidos na sua singularidade, como nos assevera Piovesan (2006, p. 22): "ao lado do direito à igualdade, surge também, como direito fundamental, o direito à diferença. Importa o respeito à diferença e à diversidade, o que lhes assegura um tratamento especial." (PIOVESAN, 2006, p. 22) Nesse sentido, respaldando a discussão proposta, Santos e Nunes (2003, p. 56) afirmam que:

Temos o direito a ser iguais quando a nossa diferença nos inferioriza; e temos o direito a ser diferentes quando a nossa igualdade nos descaracteriza. Daí a necessidade de uma igualdade que reconheça as diferenças e de uma diferença que não produ$\mathrm{za}$, alimente ou reproduza as desigualdades.

Nesse cenário, surge a emergência da descolonização dos nossos olhares, saberes e fazeres e o fortalecimento da Educação em/para os Direitos Humanos, que pode constituir um dos caminhos para a mudança, pois abarca a possibilidade de revisitarmos a nossa história e as outras histórias a partir de novas perspectivas, da escuta que efetivamente ouve, do diálogo que não fala em nome de, mas fala com, de relaçóes conjuntas e não fragmentadas que rompem com a lógica binarista "eu e os outros". Tal percepçáo nos propóe um "eu como parte dos outros", um eu como parte do mundo, pois a cultura escolar ainda é construída "a partir da matriz político-social e epistemológica da modernidade” (CANDAU, 20I I, p. 24I), 
o que corrobora a priorização do comum, do uniforme e do homogêneo, o que faz com que as diferenças sejam ignoradas ou ainda vistas como uma situação a ser resolvida, superada.

Como sabemos, a história da humanidade é marcada pela intolerância à diferença. Assim sendo, entendemos, como Garcia (1995, p. i I6), que um dos grandes desafios que se colocam à humanidade no contemporâneo é construir uma sociedade em que o diferente não seja considerado "bárbaro, mas seja respeitado em sua diferença, e possa participar da construção coletiva de uma sociedade multicultural." Entretanto, de acordo com Placer (20II, p. 88), permitimos ao Outro entrar em cena apenas para que possamos repará-lo, regulá-lo, integrá-lo e conhecê-lo: "Trata-se antes de tudo de [...] calibrar sua integração, suas ameaças, suas bondades e sua periculosidade, de legislar seus direitos e obrigaçóes, de regular seus agrupamentos, seus deslocamentos, entradas e saídas."

Duschatzky e Skliar (20I I, p. I2I) afirmam que a alteridade pode ser pensada a partir de três prismas: "o outro como fonte de todo o mal", "o outro como sujeito pleno de um grupo cultural", "o outro como alguém a tolerar." Essas formas de perceber, conceber e conviver com o outro evidenciam que é preciso e urgente assumir a diferença como um elemento constituinte do processo educativo, tendo em vista que esses são construtos das relaçóes socioculturais. Todavia, não se trata de pensar a alteridade como amor ao próximo, tampouco a partir dos ideais universais, nem sob a premissa da tolerância com a diversidade cultural, mas de pensarmos além da lógica "nós X outros", reconhecendo a nós mesmos como produto da diferença, ou seja, reconhecendo-nos na 'outridade' do outro, vendo o outro como alguém que vive em mim. "Reúna sem pretensão de unificar, articule as diferenças sem apagar os conflitos, dê espaço ao outro sem pretensão de assimilá-lo e de dissolver sua outridade." (TÉLLEZ, 20I I, p. 74). O direito à diferença é o direito à singularidade, é o reconhecimento do outro que não se determina de antemão, que escapa a qualquer identificação e controle.

De acordo com Arroyo (20I2), "o outro" foi produzido como o inexistente. Quando consideramos os outros como marginais, excluídos, desiguais, criamos possibilidades de existência para o nós e os outros. Logo, por não existirem, não há a necessidade de incluí-los, regulá-los, emancipá-los, pois são irrelevantes e incompreensíveis. A impossibilidade de sua 
copresença tem configurado uma maneira eficaz de organizar o sistema brasileiro nos campos político, social, cultural e da educação. Para evidenciar essa premissa, podemos recorrer à nossa formação sociocultural, que emergiu num contexto de mudanças vividas no continente europeu, tendo o colonialismo se estruturado no seio dessas transformações. A nossa colonização resultou em um conjunto de elementos que gerou profundas desigualdades sociais, étnicas e raciais que permanecem pulsantes até os dias atuais. A concepção colonialista serviu de base para o desencadeamento de intensas desigualdades sociais e étnicas no contexto ocidental, entre elas o racismo e as relaçóes escravocratas. Entretanto, a forma, a intensidade e a repercussão de como esses aspectos foram vivenciados no Brasil têm especificidades que os distingue dos demais países do continente americano.

Apesar de os conflitos étnico-raciais terem marcado profundamente o povoamento da América, eles só assumem o aspecto político na primeira metade do século XX, porque embora o processo de colonização tenha se encerrado a colonialidade ainda se faz presente entre nós. De acordo com Mignolo (2005, p. 34), a colonialidade representa o outro lado da Modernidade, o lado não revelado, o lado escuro, e a colonização "[...] só concebe o sistema do mundo moderno do ponto de vista de seu próprio imaginário, mas não do ponto de vista do imaginário conflitivo que surge com e da diferença colonial."

Quijano (2005) enfatiza que a América se consolidou como o primeiro espaço/tempo da modernidade, tendo como elementos pulsantes dessa constituição: a codificação das diferenças entre conquistadores e conquistados em raça e a articulação das formas de controle do trabalho, de seus recursos e também dos produtos em volta do capital e do mercado mundial. Nesse contexto, ao conceber as diferenças a partir da ideia de raça, assentavam-se uns num plano superior aos outros. Assim, a ideia de raça, em sentido moderno, só foi concebida após a história da colonização da América, sendo um dos principais argumentos nas relaçóes de dominação no projeto de conquista.

$\mathrm{Na}$ América, a ideia de raça foi uma maneira de outorgar legitimidade às relaçôes de dominação impostas pela conquista. A posterior constituição da Europa como nova identidade depois da América e a expansão do colonialismo europeu ao resto do 
mundo conduziram à elaboração da perspectiva eurocêntrica do conhecimento e com ela à elaboração teórica da ideia de raça como naturalização dessas relaçóes coloniais de dominação entre europeus e não-europeus. [...] Desde então demonstrou ser o mais eficaz e durável instrumento de dominação social universal, pois dele passou a depender outro igualmente universal, no entanto mais antigo, o intersexual ou de gênero: os povos conquistados e dominados foram postos numa situaçáo natural de inferioridade, e consequentemente também seus traços fenotípicos, bem como suas descobertas mentais e culturais. Desse modo, raça converteu-se no primeiro critério fundamental para a distribuição da população mundial nos níveis, lugares e papéis na estrutura de poder da nova sociedade. Em outras palavras, no modo básico de classificação social universal da população mundial. (QUIJANO, 2005, p. 228)

Tal realidade evidencia os efeitos da colonização na forma em que ainda hoje olhamos para o outro, ou seja, para aquele que não foi incorporado nesse projeto como o superior, o branco, o europeu, o heterossexual, o cristão. Ainda de acordo com Quijano (2005), a colonizaçáo influenciou a produção de um novo padrão mundial, produzindo também uma nova intersubjetividade. Para tal feito, a Europa atuou tanto controlando todas as formas de regulação da nossa subjetividade, da cultura e, de maneira mais incisiva, do conhecimento, quanto da sua produção, reprimindo a forma de produçáo de conhecimento dos colonizados, suas referências para a produção de sentidos, seu universo simbólico e suas formas de expressão e objetivação da subjetividade; e, ainda, obrigou os colonizados a aprenderem parcialmente sua cultura para utilizá-la nas esferas material, tecnológica e subjetiva, principalmente a religiosa. Nessa situação, podemos afirmar que o europeu transformou os não europeus em seus "outros".

Para Catherine Walsh (2009b), a colonialidade é a forma pela qual uns se sentem superiores a outros produzindo um lastro de discriminação racial. Esse projeto de colonialidade se materializa a partir de quatro eixos: a colonialidade do poder (QUIJANO, 2005), a colonialidade do saber, a colonialidade do ser e a colonialidade cosmogônica da 
mãe natureza e da vida mesma (WALSH, 2009b). A colonialidade do poder está relacionada com a questão da raça como elemento de "classificação e controle social e o desenvolvimento do capitalismo mundial (moderno, colonial eurocêntrico) que se iniciou como parte da constituição histórica da América" (WALSH 2009a, p. I4), ou ainda, como nos explica o próprio Quijano (2005, p. 20): "o problema é, contudo, que na América Latina a perspectiva eurocêntrica foi adotada pelos grupos dominantes como própria e levou-os a impor o modelo europeu de formação do Estado-nação para estruturas de poder organizadas em torno de relaçôes coloniais."

É ainda Walsh (2009b) quem expóe que a colonialidade do saber se refere ao posicionamento do eurocentrismo como ordem exclusiva da razão, do conhecimento e do pensamento. Nesse contexto, toda e qualquer outra forma epistêmica e outros conhecimentos que não incorporem essa matriz são desqualificados. A colonialidade contamina as referências epistêmicas, acadêmicas e disciplinares. A colonialidade do ser é vivenciada na inferiorização, subalternização e desumanização de alguns grupos humanos e é nessa direção que se inserem a população negra e a indígena. O último eixo, o da colonialidade cosmogônica da máe natureza e da vida, está presente na antítese natureza/sociedade, desconsiderando "o mágico-espiritual-social, a relação milenar entre os mundos biofísicos, humanos e espirituais - incluindo dos ancestrais, espíritos, deuses e orixás." (WALSH, 2009b, p. Io) Essa dimensão da colonialidade de repúdio a essas relaçôes anulou a base de vida dos povos ancestrais, tanto indígenas quanto africanos. Nessa tessitura, a colonialidade tem um sentido mais amplo para esses povos, pois a negação das suas formas de vivência induz à representação social deles como povo "não civilizado, não moderno, menos humano", evidenciando que:

[...] a diferença construída e imposta desde a colônia até os momentos atuais, não é uma diferença simplesmente assentada sobre a cultura, também não é reflexo de uma dominação enraizada só em questóes de classe, como vem argumentando grande parte dos intelectuais da esquerda latino-americana. Melhor, a matriz da colonialidade afirma o lugar central de raça, racismo e racialização como elementos constitutivos e fundadores 
das relaçôes de dominação e do próprio capitalismo (de fato enredados com as estruturas do patriarcado e os tropes de sexualidade masculinista). É nesse sentido que falamos da "diferença colonial”, sobre a qual está assentada a modernidade, e a articulação e crescimento do capitalismo global. (op. cit., p. I I)

O momento atual exige repensarmos politicamente o nosso imaginário hierárquico dos "outros", sob os quais estabelecemos uma escala de diferenciação social, política, econômica, cultural e também pedagógica. Estrutura essa que nos acompanha e marca nossas relaçóes desde o período colonial, conservando-se no período republicano, no contexto democrático e nos moldes do capitalismo explorador. Assim, devemos reconhecer a presença dos mais diversos coletivos na história da nossa formação social, política, cultural e educacional não apenas como os explorados ou marginais sub-humanos, não como "uma história que vem do alto, dos Nós do alto para os Outros de baixo: povão, negros, favelados, quilombolas, indígenas" (ARROYO, 20I2, p. I30), mas como seres de luta, resistência e reinvenção. Ao se mostrarem como sujeitos históricos, essas populações à margem do processo histórico tensionam o campo do debate epistemológico e político-pedagógico refutando a sua inexistência.

Logo, para entrar em sintonia com esse tempo, faz-se necessário que os/as educadores/as reconheçam as diferenças e sua transformação em desigualdades, compreendendo os processos históricos, sociais, culturais, políticos e econômicos que as geraram, além de serem capazes de propor açôes que se posicionem e que incidam contra toda e qualquer forma de discriminação, ou seja, precisamos implementar uma educação multicultural no cotidiano das escolas. Entretanto, não pode ser qualquer prática multicultural.

Nesse contexto, reconhecemos a perspectiva intercultural assentada na visão crítica que assume a luta por uma sociedade mais justa e equânime, vivificando a convivência entre os diferentes e valorizando o diálogo entre as culturas. É dessa forma que proporciona uma abordagem do reconhecimento do outro, orientada pela perspectiva de uma sociedade democrática, plural, humana em que se articulam políticas de igualdade com políticas de identidade, buscando cotidianamente estratégias para enfrentar as desigualdades. 


\section{O reconhecimento do outro como privilégio pedagógico: análise e discussáo dos dados}

De acordo com Arroyo (20I2), nós estamos mudando o nosso modo de ser professores porque a presença do outro tem desestabilizado as nossas práticas. Dessa forma, somos outros porque os estudantes também são outros. Para a compreensão desse panorama no CMEI foram entrevistadas a professora da turma do Grupo IV, as duas Auxiliares do Desenvolvimento Infantil (ADI) que trabalham com a turma, a coordenadora e a gestora da escola.

Gestora: Nós tivemos um estímulo grande aqui, tá? Em 2007 nós tivemos famílias da Guiné-Bissau, tá? Então isso foi uma contribuição muito grande pra nós, o conjunto que está aqui, né?! Que aqui nós nos deparamos como é, com nosso passado muito próximo, não era mais um passado, então o que já havia de passado, náo era mais o passado, era o presente que estava aqui. É aqui, com as crianças do berçário e foi nesse momento que a gente fica mais sensível pra trabalhar o que nós, a nossa realidade, trabalhar a diferença a partir de nós mesmos.

No CMEI, a partir da entrada do 'diferente' a equipe começa a se sensibilizar para a necessidade do trabalho com as diferenças. Nesse sentido, o outro não é alguém a tolerar, nem o exótico. Ele existe, é real e é respeitado. Assim, a presença do outro no CMEI ressignifica a prática pedagógica. Ele não fica à margem, no esquecimento, na inexistência, nem sujeito à homogeneizaçáo. $\mathrm{O}$ trabalho de reconhecimento das diferenças, nesse caso, caminha também para a implementação da Lei no 10.639/03, uma ação de resistência. Dizemos resistência porque essa discussão vem permeada por olhares atravessados, negaçôes, convencimentos e carência de materiais. Assim, não é simples, tampouco fácil.

ADI r: Pra muita gente é: já vai falar sobre isso de novo? É como se a gente precisasse falar de outras coisas. E assim, já houve situaçôes bem simples: - Ah, oh, por que a gente não vai falar sobre outras culturas, por que vocês só querem falar 
da cultura negra? E aí a gente destaca que outras culturas já são bastante valorizadas pela mídia. [...] E a gente já começa a perceber que não é uma discussáo [...] nem pra fulano ou beltrano, mas é uma discussão pra toda a comunidade, a gente ainda nesse momento atual, mais de três anos que a gente vem discutindo sobre isso na unidade a gente ainda encontra resistência de algumas pessoas porque acha que não é preciso falar sobre isso porque a gente não encontra preconceito, não consegue perceber o preconceito. [...] Mas é uma briga eterna e não é fácil porque quando a gente mexe com isso, mexe também com as famílias, né? Mexe com essa questão do pertencimento, mexe com a questão de se identificar, né? $\mathrm{E}$ às vezes se identificar não é algo fácil porque mexe com um monte de outras coisas que estão lá guardadas ou que vêm lá da família e que não é muito fácil, né?

Salientamos que a proposição de práticas educativas que visam à descolonização dos saberes não se inseriria no espaço escolar sem tensões. A implementação da Lei no 10.639/03 que altera a LDB e estabelece as Diretrizes Curriculares para sua implementação, instituindo a obrigatoriedade do ensino da História da África e dos africanos no currículo escolar dos níveis fundamental e médio, é um exemplo disso: embora seja lei, a sua vivência não está contemplada no currículo de muitas escolas, bem como não há um convencimento unânime de que tais questôes devam ser tratadas. Também não há uma preparação da maioria dos docentes para tal, uma vez que socialmente essas questóes não são visibilizadas. Ao ser indagada sobre por que trabalhar a temática das relaçóes étnico-raciais no CMEI, a professora respondeu:

Enquanto professora da rede, né? A gente entende que é uma obrigação no sentido de ser lei e das cobranças, né? Eu sempre brinco aqui quando alguém questiona porque também já foi questionado por se tratar essa temática, porque só se fala do negro nessa creche, que já se perguntou isso. Eu digo: - Olha, eu tenho alguns argumentos que já foram vencidos nesse meu discurso, com algumas pessoas. Oh, só! Abre a caderneta, lá 
tem um campo específico que diz isso, porque aí eu tive que apelar infelizmente porque é lei. Mas, eu não trato apenas porque é lei. Eu trato porque eu acho que é realmente importante ter outras histórias para além da história que nós aprendemos. Eu até perguntei pra essa pessoa que me perguntou isso (sobre o porquê de trabalhar as relaçôes étnico-raciais) se quando ele escutava histórias de negros, histórias que tratavam de questáo étnica, que não fosse um negro escravo, um negro que apanhava o tempo inteiro. Enfim, ele não conseguiu me responder. Eu disse: - Pronto. Um dos motivos que eu trato é para reverter essa história que nós aprendemos dessa forma e aí por que nossas crianças não têm o direito de ouvir essas histórias contadas sobre outra ótica?

De acordo com Nilma Lino Gomes (20I0), as escolas brasileiras públicas e particulares necessitam revisitar suas posturas, valores, conhecimentos e currículos no intuito da reeducação para as relaçôes étnicoraciais, pois, na atualidade, precisamos superar, entre outras questóes, a subalternização dos saberes produzidos pela comunidade negra, a existência de estereótipos raciais nos livros didáticos, a estigmatização do negro, os apelidos e xingamentos raciais e a versão pedagógica do mito da democracia racial, não apenas pelo compromisso social e pedagógico da escola com tais questóes, mas também pela força da lei. Reconhecendo essa premissa, a professora utiliza-a para o convencimento daqueles que a questionam sobre as práticas vivenciadas no CMEI. Assim como Gomes (20I0), a professora revela as inúmeras resistências e reconhece que é pela força da Lei que a questão racial começa a ser pedagógica e também politicamente assumida pelo Estado, pelas escolas, pelo currículo e na formação inicial e continuada dos docentes no Brasil.

De acordo com Gomes (2006, p. 33), "não podemos acreditar numa relação causa e efeito entre o preceito legal e a realidade social e educacional", pois, embora a lei represente um grande avanço, é no seu embate político, no contexto das relaçóes de poder, na rotina da escola e na organização e vivência das práticas educativas que ela vai ser concretizada. Assim, para que a sua implementação se configure, é primordial um contexto de respeito às diferenças. 
Ao propor a reescrita do conhecimento escolar, a professora defende a visibilidade dos sujeitos ocultados do currículo escolar, para que possamos conhecer e recontar a sua história por suas vozes, podendo a escola ser uma possibilidade da construção de autoimagem positiva dos educandos. O que ela propóe condiz com o que afirmam Moreira e Candau (2008, p. 32), almejando que no currículo "os interesses ocultados sejam identificados, evidenciados e subvertidos, para que possamos, então, reescrever os conhecimentos.” No cerne dessa proposição está a possibilidade de explorar e confrontar novas perspectivas, abrindo o currículo para novos enfoques e intenções, fazendo emergir as motivações, as seleçôes, as disputas, as relaçóes de poder, bem como as repressóes, silêncios, ocultaçóes, exclusōes.

A equipe ainda expóe que a proposição da reeducação das relaçóes étnico-raciais tem desdobramentos na construção da identidade da criança e negra, mas embora se busque fortalecê-la na escola por inúmeras estratégias ela convive num universo mais amplo no qual nem sempre a sua cor e seus traços físicos são valorizados. Dessa maneira, a criança reconhece desde cedo o que é socialmente tido como bom e bonito, ou seja, o que traz prestígio, como podemos ver salientado na fala de outra ADI:

ADI 2: Na minha opinião é importante trabalhar por causa da autoestima, muitas crianças negras, elas querem se parecer com as crianças brancas, elas querem alisar o cabelo, muitas vezes eu vejo algumas crianças comentando: -Tia eu quero dar chapinha no meu cabelo e quero alisar o cabelo. Elas náo acham o cabelo bonito e muitas dizem quando veem uma tia com o cabelo liso, estirado: - Ah, o seu cabelo é lindo, não é? E ficam mexendo, mexendo com aquela admiração, aí gente pergunta: - E o seu, não é bonito? - Não, eu queria que fosse parecido com o da senhora. Entấo, eu acho que principalmente para trabalhar a questấo da autoestima delas, não é? Delas se aceitarem, delas gostarem delas, não é? E também a relação com o outro. [...] E aí, da aceitação das diferenças.

Atentar para a necessidade de construção da autoestima representa o entendimento da singularidade de cada criança na sua forma de sentir, pensar, agir, viver e conviver no mundo. Nesse sentido, as estratégias pe- 
dagógicas focadas na construção positiva da imagem da criança e negra ajudam as crianças a valorizarem seu corpo, cabelo, jeito de ser, sua cor, sua cultura. Consideramos ainda que as prática invasivas, muitas vezes, realizada na Educação Infantil, sob o pretexto de higiene corporal, entre elas, destacamos a negaçáo do direito da criança e negra de manter o seu cabelo solto sob o pretexto de que é preciso mantê-la arrumada, constrangem a estética corporal dessas crianças impondo a elas um modelo socialmente valorizado, para que correspondam ao desejo de serem aceitas pelas demais.

Santana (2006) nos mostra que a relação entre os estabelecimentos que ofertam a Educação Infantil e as famílias ocorre num cenário de conflitos que necessita ser construída no contexto do diálogo constante, da escuta sensível e acolhedora, almejando o entendimento da conjuntura na qual essas histórias de vida são construídas. Cuidar do cabelo é uma questão vivida pelas crianças e negras desde muito cedo. Esse é, todavia, um trabalho que não se esgota com essa ação. Foi importante também repensar os materiais, conforme exposição abaixo:

Coordenadora: Então, a gente começa a fazer um trabalho avaliando os recursos que a gente possuía e via que a gente tinha uma pobreza de recursos, de livros, de brinquedos, de tecidos, de musicalidade e aí foi a gente há 7 anos, [...] há cerca de 6 anos, a gente começa investir em ampliar o nosso repertório, o nosso fortalecimento para ter um trabalho mais eficaz. [...] Você viu que a portinha que eu abri (porta do armário) tinha uma prateleira com o material, eu disse: - Oh, o material tá aqui nessa prateleira, mas é muito pouco, uma prateleira, um material que é para tá disponível, né, é muito pouco.

Gestora: Outra dificuldade na nossa formação é ter o material, tá, e ter um material voltado pra literatura infantil. Ele é pouco, caro, então quando a gente consegue queira ou não, a gente começa a não colocar ele muito acessível, é aquele livro que está na sala dos professores, você pode pegar e tirar, mas não é aquele que você deixa na sala. É importante ficar vários livros na sala, então, é caro, é caro, então, isso dificulta, né? 
Ao inserirem materiais que contemplam a diversidade étnico-racial no CMEI, a equipe está se permitindo o diálogo intercultural, pressupondo que outras formas de organização são possíveis, reconhecendo que a cultura da população negra foi, por séculos, ignorada e que é preciso reinventar a escola. Mas reconhecendo a escassez de material e o seu alto preço de mercado, a escola não abre portas, abre ainda frestas que iluminam a construção da identidade das crianças. Porém, nem todas as frestas possibilitadas nas variadas instituiçóes educativas têm produzido os mesmos resultados. Arroyo (20I0) destaca que muitos desses espaços que têm sido abertos para as questôes das relaçóes étnico-raciais reduzem o diálogo intercultural a uma abertura festiva e seletiva, o que de outra forma também notabiliza o desrespeito à história da população negra. Assim, tem sido comum que em momentos festivos da escola e/ou de formação de professores, entre outros, que esses coletivos sejam convidados a apresentar coreografias de capoeira, rap, funk, maculelê, maracatu, samba, enfim, de inúmeras expressôes da cultura negra. Mas essas açôes pontuais são "formas de 'incorporação', reproduzem e não modificam a tradicional função reguladora do sistema sobre o que sejam concepçóes legítimas de saberes, valores, cultura, identidade." (ARROYO, 2010, p. I27) No entanto, as práticas apresentadas no CMEI certificam que não é esse o percurso em construção.

Professora: Para além da contação de história, a gente recheou a nossa sala de faz-de-conta de bonecas negras porque era uma outra coisa que até aquele ano a gente não tinha percebido. [...] Então, as bonecas negras além da gente ter dificuldade de encontrar, né? Elas também tinham um preço alto, a não ser que fosse aquela boneca muito vagabunda, mas se fosse aquela boneca que a gente gostasse de estar com ela no colo e aí a gente ficava olhando: tem cabelo? Nấo tem cabelo? Por que todas são carecas? Por que todo bebê negro é careca? Aí a boneca negra que já era adulta tinha cabelo liso. Então, quando a gente começava a procurar nossa especificidade, a gente vê que cada vez fica mais caro. Mas, ainda assim, como é que a gente faz? Como é que a gente coloca dentro do nosso orçamento para não fugir? E aí a gente foi investindo, não só nas bonecas negras mesmo, 
porque a boneca negra de tecido parecia uma Emília, uma bruxinha, não era? Aí, a gente percebia que os meninos começavam a se interessar também, a gente observa que precisávamos ter meninos e meninas [...]

As estratégias apuram que as crianças e negras viviam num contexto de desigualdade na escola. Nesse sentido, como sujeito de direitos, elas precisam ver-se representadas no espaço escolar, ou seja, elas têm o direito de vivenciar a sua cultura na escola, a partir da desconstrução do caráter monocultural e etnoeurocêntrico das práticas educativas. O depoimento acima, porém, também deixa atentar que os meninos e negros foram pensados como um público a ser atendido no contexto do reconhecimento das suas diferenças. Eles demoraram a ser representados na forma dos bonecos, bem como não observamos, ao longo dos discursos da equipe, estratégias que dessem visibilidade à sua identidade de menino e negro. Há especificidades de gênero que precisam ser consideradas nessa discussão: ser menina e negra é diferente de ser menino e negro, e essas especificidades precisam ser consideradas em todas as estratégias que almejem a reeducação das relaçóes étnico-raciais.

A diferença construída a partir das variadas culturas dos sujeitos que constituem o CMEI, como estudantes, traz à tona a necessidade da compreensão de que as diferenças precisam se constituir como privilégios pedagógicos, uma vez que estamos adaptados a um círculo vicioso que nos impulsiona a pensar uma proposta unificada sem considerar realmente as características dos estudantes - a latente diferença traz novas possibilidades e novas aprendizagens, ou seja, é preciso descolonizar o saber. O Outro possibilita novas compreensôes da organização do processo educativo proporcionando intercâmbios, trocas e aprendizagens mútuas.

\section{Consideraçóes finais}

A pesquisa no CMEI evidenciou o compromisso da equipe entrevistada com uma Educação em/para os Direitos Humanos que reconhece o direito à diferença e assume a luta contra a discriminação e desigualdade social e racial. Contexto esse assumidamente fincado numa perspectiva 
contra-hegemônica de construção social, política e filosófica da escola. Os discursos e as práticas observadas nos permitem evidenciar a importância de alguns elementos propostos por Candau (2012) sob a perspectiva intercultural, tais como: as estratégias do cuidar/educar que buscam a desconstrução do caráter monocultural da educação pela reconstrução da amnésia à qual a história da África foi exposta, bem como pela valorização de elementos da cultura negra e seus elementos identitários; o reconhecimento das desigualdades nas quais os estudantes estão inseridos e a luta pela modificação desse cenário; e a promoção de experiências de diálogo com o outro através do reconhecimento da sua cultura.

Coerente com essa situação, Abramowicz e Levcovitz (2010) destacam que a diferença precisa ser retirada desse lugar do estranho, do horrível, da aberraçáo, da cena em que foi satanizada, para que a criança possa construir novas possibilidades de agenciamentos, afetos e amizades. Dias (20I2) reforça esse argumento salientando que é preciso considerar as diferenças entre as pessoas como valor positivo, exacerbando que é importante nos posicionarmos contra políticas de identidade que estabelecem hierarquias entre as pessoas, processo em que a diferença se torna algo negativo. E essa possibilidade começa a ser construída no CMEI.

Assim, a partir dos dados podemos inferir que as práticas vivenciadas no CMEI têm contribuído para que as crianças percebam as diferenças como algo positivo e para que as crianças negras, ao se reconhecerem como tal, orgulhem-se disso. Nesse sentido, as práticas buscam legitimar cada um dos/as estudantes presentes na escola, trabalhando na construção e vivência de metodologias que visem romper com o silenciamento, ocultação, invisibilidade e inferiorização de determinados grupos sociais, a partir de práticas críticas e questionadoras dos princípios colonizadores existentes.

Nessa perspectiva, salientamos a importância de se organizar e propor, desde a Educação Infantil, a vivência de práticas que não se estruturam apenas pela valorização das características da diversidade, mas na reflexão de como as diferenças foram e são usadas para reproduzir as desigualdades e na luta para que essas não se legitimem como tal. Assim, a interculturalidade que almejamos é, "em última instância, um sonho, mas um sonho que se sonha na insônia da práxis.” (WALSH, 2009a, p. 28) 


\section{Referências}

ABRAMOWICZ, Anete. A pluralidade de ser judeu. In: GOMES, Nilma Lino; SILVA, Petronilha B. Gonçalves (Org.). Experiências étnico-culturais para a formação de professores. 3. ed. Belo Horizonte: Autêntica, 20I I. p. 27-38.

; LEVCOVITZ, Diana. Tal infância. Qual criança? In: Afirmando diferenças: montando o quebra-cabeça da diversidade na escola. Campinas, São Paulo: Papirus, 20I0, p. 73-86.

ARROYO, Miguel Gonzáles. A pedagogia multirracial popular e o sistema escolar. In: GOMES, Nilma Lino (Org.). Um olhar além das fronteiras: educação e relações raciais. Belo Horizonte: Autêntica, 20Io. p. I I I-I30.

. Outros sujeitos, outras pedagogias. Petrópolis: Vozes, $20 \mathrm{I} 2$.

BRASIL. Lei no 10.639, de 9 de janeiro de 2003. Altera a Lei no 9.394, de 20 de dezembro de 1996, que estabelece as diretrizes e bases da educaçáo nacional, para incluir no currículo oficial da Rede de Ensino a obrigatoriedade da temática História e Cultura Afro-Brasileira, e dá outras providências. Brasília, DF, 5 jan. 2003. Disponível: <http:// www.planalto.gov.br/ccivil_03/leis/2003/lio.639.htm>. Acesso em: Io abr. 2018.

CANDAU, Vera Maria. Didática crítica intercultural: aproximaçóes. Petrópolis: Rio de Janeiro: Vozes, 2012.

Multiculturalismo e educação: desafio para a prática pedagógica. In:

MOREIRA, Antonio Flávio; CANDAU, Vera Maria (Org.). Multiculturalismo: diferenças culturais e práticas pedagógicas. Petrópolis: Rio de Janeiro: Vozes, 20I I. p. I3-I7.

. Sociedade multicultural e educação: tensôes e desafios. In: (Org.).

Cultura(s) e educação: entre o crítico e o pós-crítico. Rio de Janeiro: DP\&A, 2005, p. I3-37.

DIAS, Lucimar Rosa. Formação de professores, educação infantil e diversidade étnico-racial: saberes e fazeres nesse processo. Revista Brasileira de Educação, v. I7, n. 5I, p. 66I-749, set./dez. 2012.

DUSCHATZKY, Silvia; SKILIAR, Carlos. O nome dos outros: narrando a alteridade. In: LARROSA, Jorge; SKILIAR, Carlos. Habitantes de Babel: políticas e poéticas da diferença. 2. ed. Belo Horizonte: Autêntica Editora, 20I I, p.II9-I62.

GARCIA, Regina Leite. Currículo emancipatório e multiculturalismo: reflexôes de viagem. In: SILVA, Tomaz Tadeu da; MOREIRA, Antônio Flávio (Org.). Territórios contestados: o currículo e os novos mapas políticos e culturais. Petrópolis: Vozes, I995. p. II4-I43.

GOMES. Diversidade cultural, currículo e questão racial: desafios para a prática pedagógica. In: ABRAMOWICZ, Anete; BARBOSA, Lúcia Maria de Assunção Barbosa; SILVÉRIO, Valter Roberto. Educação como prática da diferença. Campinas, SP: Armazém do Ipê, 2006. p. 2I-40. reflexôes. In:

Diversidade étnico-racial e Educação no contexto brasileiro: algumas 
. (Org.). Um olhar além das fronteiras: educação e relaçôes raciais. Belo Horizonte: Autêntica, 2010.

MCLAREN, Peter. Multiculturalismo crítico. São Paulo: Cortez, I997.

MIGNOLO, Walter. A colonialidade de cabo a rabo: o hemisfério ocidental no horizonte conceitual da modernidade. In: LANDER, Edgardo. A colonialidade do saber: eurocentrismo e ciências sociais - perspectivas latino-americanas. Buenos Aires: CLACSO, 2005.

MOREIRA, Antônio Flávio Barbosa; CANDAU, Vera Maria. Multiculturalismo: diferenças culturais e práticas pedagógicas. Petrópolis: Vozes, 2008.

PIOVESAN, Flavia. Como compreender a concepção contemporânea de direitos humanos? Revista USP, São Paulo, n. 69, p. 36-43, mar./maio 2006.

QUIJANO, Aníbal. Colonialidade do poder, eurocentrismo e América Latina. In: LANDER, Edgardo (Org.). A colonialidade do saber: eurocentrismo e ciências sociais. Buenos Aires: Conselho Latino-americano de Ciências Sociais - CLACSO, 2005.

SANTANA, Patrícia Maria de Souza. Educação Infantil. In: BRASIL. Ministério da Educação/Secretaria da Educação Continuada, Alfabetização e Diversidade. Orientaçóes e açóes para a educação das relaçóes étnico-raciais. Brasília: SECAD, 2006. p. 27-49.

SANTOS, Boaventura Santos; NUNES, João Arriscado. Introdução: para ampliar o cânone do reconhecimento, da diferença e da igualdade. In: SANTOS, Boaventura Santos; (org.). Reconhecer para libertar: os caminhos do cosmopolitismo multicultural. Rio de Janeiro: Civilização Brasileira, 2003, p. 25-68.

SILVA, Petronilha Beatriz Gonçalves. Pesquisa e luta por reconhecimento e cidadania. In: ABRAMOWICZ, Anete; SILVÉRIO, Roberto (Orgs.). Afirmando diferenças: montando o quebra-cabeça da diversidade na escola. Campinas, SP: Papirus, 20Io. p. 27-54.

TÉLLEZ, Magaldy. A paradoxal comunidade por-vir. In: LARROSA, Jorge; SKILIAR, Carlos. Habitantes de Babel: políticas e poéticas da diferença. 2. ed. Belo Horizonte: Autêntica editora, 20I I. p. 45-78.

WALSH, Catherine. Interculturalidade crítica e pedagogia decolonial: in-surgir, re-existir e re-viver. In: CANDAU, Vera Maria (Org.). Educação Intercultural na América Latina: entre concepçôes, tensóes e propostas. Rio de Janeiro: 7 Letras, 2009a. p. I2-42.

. Interculturalidade e (des) colonialidade: perspectivas críticas e políticas. In:

CONGRESSO ARIC, I2., 2009, Florianópolis. Anais... Florianópolis: ARIC 2009b.

\section{Recebido em 3I jan. 2018 / Aprovado em 20 mar. 2018}

Para referenciar este texto

SILVA, T. R.; DIAS, A. A. A educação infantil e as práticas pedagógicas descolonizadoras: possibilidades interculturais. EccoS-Revista Cientifica, São Paulo, n. 45, p. II7-I36. jan./abr. 20I8. Disponível em: < https://doi.org/I0.5585/EccoS.n45.83I4>. 